\title{
"Liquid/Cloudy/Foggy: For a Critique of Fluid Textuality"
}

\section{Massimo Riva, Brown University}

\begin{abstract}
The title of this paper is inspired by the book edited by Domenico Fiormonte entitled Canoni liquidi (Liquid Canons). Of course, the adjective "liquid" refers to Zygmunt Bauman's term at which my critique is also indirectly aimed. The title of Fiormonte's book seems to suggest equivalence between textual "mobility" and "liquidity." Yet the "liquefying" of (literary) canons and the emergence of new intrinsically kinetic or fluid forms of mobile textuality requires a critical assessment that does not prematurely celebrate the funeral of the text as we know it but pays close attention to what seems to be waiting for us beyond the text, as suggested in Francesco Fiorentino's recent edited volume. This means paying attention to what in my recent book, Il futuro della letteratura (The Future of Literature), I call digital incunabula: objects/textual tools, devices programmed in a twofold, reciprocal sense, whose linguistic properties and rules interact and interfere with the algorithmic procedures of artificial languages. In this programmed and programmable interaction and intermediation one can perceive the horizon of incomprehensibility of posthuman language, providing a new aporetic dimension to Gadamer's assertion that "the being that can be understood is language." This assertion is by now the most significant issue in the horizon of literary (digital) arts.
\end{abstract}

Il titolo di questo saggio si ispira (e reagisce) a quello del libro curato da Domenico Fiormonte Canoni liquidi. Naturalmente, l'aggettivo rimanda al termine reso corrente da Zygmunt Bauman che rimane sullo sfondo della mia critica. Il titolo del libro di Fiormonte sembra suggerire una equivalenza tra testo "mobile" e "liquido." Ma la liquefazione (e liquidazione) dei canoni (letterari) e l'emergere di nuove forme di testualità intrinsecamente cinetica o fluida richiedono una valutazione critica che non celebri prematuramente il funerale del testo, come lo conosciamo, ma presti attenzione a quello che sembra attenderci "al di là del testo" (per parafrasare il titolo del libro curato da F. Fiorentino con cui dialogo nel mio intervento). Nel mio e-book sul futuro della letteratura dedicato all'opera d'arte letteraria nell'epoca della sua (ri)producibilità digitale, ho affrontato la questione dal punto di vista di quelli che definisco "incunaboli digitali": oggetti/strumenti testuali, dispositivi programmati in un duplice, reciproco senso, in cui le proprietà e le regole del 
linguaggio (letterario) inter-agiscono e inter-feriscono con le procedure algoritmiche dei linguaggi "artificiali." In questa inter-azione o intermediazione programmata e programmatica si delinea l'orizzonte di incomprensibilità del linguaggio post-umano, dando una nuova dimensione aporetica all'asserto di G. Gadamer (citato da F. Fiorentino) che "il linguaggio è l'essere che può essere compreso." Questo asserto è ormai la domanda che si staglia all'orizzonte delle arti letterarie (digitali).

My essay discusses three books, including mine, and all that follows should be considered as a series of remarks suggested, or provoked, by my reading of the two books edited by the organizers of the conference "Il Testo è mobile," held in Rome on January 10, 2012.

The very title of this paper is inspired by the book edited by D. Fiormonte and entitled Canoni liquidi (Liquid Canons). Of course, the adjective "liquid" refers to the term coined by Zygmunt Bauman at which my critique is also indirectly aimed. The title of this symposium seems to suggest equivalence between textual "mobility" and "liquidity." Yet, the "liquefying" of (literary) canons and the emerging of new forms of mobile textuality require a critical assessment that does not prematurely celebrate the funeral of text as we know it but pays close attention to what in my book about the future of literature in the age of its digital (re)production I have defined digital incunabula (Riva, Il futuro della letteratura)

The loss of centrality of Text is not a taboo any more, in the humanities. Rather, it is now seen as an opportunity for a theoretical and methodological turn, which would bring the humanities closer to current developments in the social sciences or even the life sciences. I am thinking of the "neural" or "neurological" turn in cultural studies, for example. Yet, whether we embrace this opportunity or not by and large depends on a fundamental ambivalence that we humanists deep down feel in an age in which models and forms (as well as canons) inherited from the past are not only "liquefied" but also, apparently, "liquidated" on the digital platform. As humanist and literary scholars, we are committed to the preservation of our past, the repository of our literary heritage, as much as we are to the construction of our future, the re-generation of that heritage within the new mode of cultural production. Yet, we do not often see clearly enough how the two things actually go together - indeed too often we see them as goals opposing each other. The only way out of this ambivalence is to realize that our own contribution to the development of the digital mode of cultural production entirely depends on our ability to boldly convert and re-invent within it models and forms inherited from our cultural (literary) past.

Disenfranchising Text from the history of print culture is something that the literary (digital) avant-garde has been doing for at least the past twenty years, continuing the mission that historic avant-gardes (in the early $20^{\text {th }}$-century and the $1960 \mathrm{~s}$ ) had already undertaken. When, in Il futuro della letteratura, I speak about the future of literature, therefore I mean both the entirety of "works" tagged or codified as such in our cultural 
archives and the symbolic form of cultural production which is undergoing today a radical transformation: now more than ever, the survival of the first (the repository, our literary memory) and that of the second (the cultural form, our literary imagination) depend on each other. As our literary heritage turns into a cloud of (textual) data, the cloud itself changes shape. Today practically all of "literature" - artifacts made of language - is digital, including the literature that gets printed. In my book, I speak about those artifacts that are born digital, that is, literary artifacts intentionally produced with programmable devices. Of course, the literary text is always already a programmed linguistic, stylistic and rhetorical device: it is programmed by the author - and sometimes re-programmed by the reader - to do something, tell a story, recite a poem, etc., according to more or less strict linguistic, that is grammatical, syntactical, semantic rules or constraints.

From this point of view, the (literary) text can be considered the software of the literary machine. From another point of view, however, one can consider the text itself as the machine, the programmable device. Yet another perspective considers the hardware and software inextricably intertwined, as in a printed book, or an e-book. Now, in the age of digital incunabula, as it moves from print to electronic formats, the literary text undergoes (or is augmented by) another programming layer. Literary codes do not transfer untouched from a medium to the other. To speak of different "supports" for the same text is therefore utterly inadequate. Under the hood of the literary machine, different forms of language (human, mechanic, or machinic, "natural" and "artificial") interact and often interfere with each other. But here is the important thing: when we speak of programming or reprogramming text (or the literary work of art as a textual device), we mean both the reprogramming of linguistic codes or rules according to the procedural protocols (algorithms) of computing devices and the programming or reprogramming of digital devices in order to process and perform literary procedures: the "textual instruments" of which, for example, speak John Cayley or Noah Wardrip-Fruin (two of the artists I consider in my book) are complex, multilayered devices in which programming and literary codes expressively interact with each other (Riva 179-180).

The result of this inter-action, or, to quote Kate Hayles, "inter-mediation" between literary and computing codes is to produce hybrid symbolic-artificial objects (artifacts): indeed, in my book I also claim that the Hybrid, in this sense, emerges as the most compelling ontological genre (or category) of digital literature, the ontological mode of a multi-layered, programmable device (Hayles, Electronic Literature 51; Riva 105). The most interesting and, from my point of view, successful works of digital literature about which I write, are those which highlight this hybrid ontology of programmed literary objects, without sacrificing the pleasure that we traditionally associate with the literary experience. This pleasure is only partially due to the surprise and wonder effect produced by the mobility acquired by the text. Rather, as Espen Aarseth argued in Cybertext. Perspectives on Ergodic Literature, a book published fifteen years ago, it also depends on the active, ergodic role of the "reader" or "user" or co-producer (cyber-text releases a high degree of ergonomic energy). But what does this all mean, exactly? Granted, human culture is not text-centric 
anymore, perhaps we are indeed moving beyond the text, to quote the title of the book edited by Francesco Fiorentino. Fifteen years ago, Mario Ricciardi edited a similar book entitled Oltre il testo: gli ipertesti (Beyond Text, HyperText) which seemed to provide an easy answer to the question about the future, or the "beyond," of textuality. Those were the years in which the meta-model of the net (or the web) was beginning to impose itself: the beyond of textuality seemed to be its empowered version, Hyper-Text in both its social and cognitive meaning. Yet, fifteen years later, we are not so sure that our ever more powerful or hyper-linguistic devices are indeed only that (the computer as an alphabetic machine, as Umberto Eco used to say). ${ }^{1}$ Beyond the declining fortune of literary hypertexts a more radical questioning seems to emerge, in Fiorentino's introduction to his book, where he writes: "With the digital revolution the age has come to an end in which we could think, with G. Gadamer, that 'the being that can be understood is language" " (Fiorentino 16).

In short, this is really the "beyond" that we have to envision. The mobility of text is only an epiphenomenon of this more profound transformation. Consciousness-language-writing: this hermeneutic circle (which also included the Freudian un-conscious) is now inserted in a more complex circuit, in the age of programmable media. This is the issue facing the humanities as they come to consider (to say "understand" would be excessive) the alphanumeric, and algorithmic properties of our hybrid cultural devices. Indeed, Understanding as the mode of humanistic thinking (according to the tradition that dates back to W. Dilthey) is now a questionable tenet, albeit one perhaps the humanities should preserve. The digital mode of production is based on a different ontology in which (I quote again Fiorentino) textuality is no longer able "to capture all the knowledge that an epoch or a society has of itself" (Fiorentino 23). This is indeed the paradox we are confronted with: at a time when written communication seems to literally explode and (paraphrasing an old Latin proverb) scripta volant everywhere, writing in its strict linguistic sense loses its privileged epistemological status within our culture. This is not simply due to the fact that our cultural processes "are nowadays embedded within a plurality of media" (Fiorentino 23). (Wasn't this always so? Only the hegemony of text in print culture has obscured the intrinsic multimediality of human culture, across the ages). And it is not only due to the fact that, since the 1960s, with Barthes, Derrida, Foucault, Deleuze and Guattari, etc., the "mobility" of writing has been unleashed, liberated from its metaphysical constraints. Perhaps more than anything else, it is the demise of the Book as a cultural meta-model in the postGutenberg era that un-bound the text, both in a physical and a symbolic sense. The Book as metaphor of the World has been replaced by the Net. Fiorentino speaks of "infinite nets" in his introduction to his book (9-59). Even the (modern) Encyclopedia from this point of view was a meta-book. Thinking in terms of Networks (rather than Corpora or Canons, for example) has become a commonplace even for humanists, as texts lose their corporeal features and become assimilated to dis-continuous, disembodied processes.

So the question we have to ask ourselves really is: what awaits us, not beyond Text, but beyond Hyper-Text? In my book, I suggest that the best electronic or digital literature invites us to consider precisely this question. HyperText, of course, emerged in the 1960s as an 
exquisitely literary construct: later, Ted Nelson explicitely spoke of the literary inspiration of his idea of hyper-text as expressed in the title to his book, Literary Machines. Yet, Hypertext as a genre (or a model) of digital literature flourished later and withered. Already years ago, Bob Coover spoke (somewhat nostalgically) of hypertext as the golden age of electronic literature, already over at the turn of the last century. Yet, all forms of digital literature have this in common with the hypertexts of yesteryear: they consciously, intentionally, reflectively adopt the computer or other programmable devices as their "posttextual" instruments. Not just to disrupt the "linear" logic of traditional narrative or recalculate the constraints of poetic forms. But to re-think our own primary connection with Language as the only understandable mode of human being. Beyond Language, beyond Understanding.

The artists of which I write in my book present us with an interesting critical paradox: they work in a niche, undoubtedly (when all the culture is somewhat, at least technologically, converted into avant-garde, avant-garde is reduced to a niche). Yet, in their work they move beyond the contamination or hybridization of the meta-model of the Book with the meta-model of the Net (Riva 299-304). In other words, they move beyond the metamodel of Hyper-Text, the cognitive translation of the intrinsic hyper-mobility of Language, in order to venture into the uncharted territory of the hybrid, natural-artificial processing of language, which, supposedly, across our previous evolutionary stages, has made us human (all too human). In doing so, however, these artisans of the techno avant-garde maintain an organic link with the old repository of literary imagination: they experiment with the literary codes inherited from the past, especially the procedural algorithms of the historic avant-gardes, putting them to the test of the new instruments or devices - and in doing so, they claim a somewhat hybrid but progressive identity as writers.

And here we come to the heart of my argument and my conclusions. In a book of a few years ago, Arturo Mazzarella spoke of the "great net of writing," in praise of (literary) Writing. It is true, he wrote, that within our cultural mode of production writing increasingly "hybridates" itself with video art, digital cinema, computer games, virtual communities, social networks etcetera. Yet Writing, according to Mazzarella, maintains a fundamental power: "the capacity of going back to its origins: to the material pregnancy of the word, combined with the virtuality naturally imprinted in writing, whose indeterminacy assures its absolute plasticity" (Mazzarella 118). I have italicized in this quotation the terms that I find both suggestive and highly problematic. The history of writing, as we know, hardly justifies a meta-physics of the Origin: indeed, the latest forays into the origins of writing suggest a closer relationship between language and calculus than the traditional division of the two cultures was able to accept (Grigorenko).

As for the material pregnancy of the word, it is always embedded in, and dependant on, the specific tools and media in which the word finds concretization: there is nothing exclusively natural in it; it is an exquisitely technological device. And finally: of which indeterminacy does Mazzarella exactly speak (write) here? A linguistic or a semantic one? Is the plasticity to which he alludes the capacity of Writing to break and renew its own rules and procedures? If so, is this 
plasticity a natural or a hybrid quality: isn't the process of writing always embedded in a technological inter-mediation? And doesn't the degree of plasticity precisely depend on this intermediation? Moreover, we may ask whether this praise of the intrinsic plasticity, indeterminacy and fluidity of Writing is sustainable from both a conceptual and a realistic point of view; or whether it should be simply considered an effect of the digital mode of production, a retrospective projection of properties that belong to the latter. I would argue the latter.

Perhaps, in our contemporary context, it does make more sense to speak of "liquid" or "fluid" writing than "solid" literature. Yet, one must ask, is the price to be paid for the loss of an understandable notion of "literature"? Fiorentino celebrates our newly acquired freedom to venture "diasporically" (thanks to the hyper-mobility of texts, once all canons are liquified) beyond our traditional institutional and territorial boundaries. It is limiting indeed to speak "only" of "literature" instead of "infinite nets," understood as a new meta-cognitive model. If we accept this position, criticism will then become "a set of variously intertwined epistemological practices which trace knowledge paths in the Cultural Hyper-text" (Fiorentino 59).

My final question then is about the specific medium of this set of practices, distributed, pervasive, or interstitial within the cultural rhyzome. According to Fiorentino, they consist in a "multitude of texts which are connective machines of diverse enunciations" (Fiorentino, 58) - Fiorentino also uses the term "script" and "score" (as in cinematic and musical writing). These definitions are certainly consistent, in principle, with the definition of "textual instruments," mentioned above. The question is: what kind of Writing are we talking about? Are we sure that Mazzarella, Fiorentino, Cayley, etc. mean the same thing when they talk about writing? Isn't our concept of writing, so "plastic," so "liquid," so "fluid" a little too cloudy or foggy, or fuzzy, if we do not specifically reflect (on) it from the point of view of the hybrid textual-algorithmic devices and the objects they produce, within the digital eco-system?

In short, we have to consistently ask ourselves how writing is specifically mediated today, through our multiple programmable devices. What kind of interface is/processes literary writing, today, as a cultural software? (Manovich) In order to answer this question we must begin by questioning the deceptively commonsense notion of an immaterial, entirely fluid textuality. Perhaps, one effective way to examine this ideological fluidity - the ideology of a free, unbound, anarchic circulation of textual currency - is to devise ways to interrupt the ever spinning, spiraling cycle of the hyper-textual machine. ${ }^{2}$ How can literary (expressive) software interfere with the automatism of our self-programming cultural machine? How can it allow us to critically reflect, from both an emotional and cognitive standpoint (as is the prerogative of great works of literary art) on the way in which language transforms itself in its interaction with programmed devices? In the best possible cases, such a reflective approach (perhaps as an antidote to the widespread ludic enthusiasm for faster and faster computer gaming) can help us pose again, within our new cultural mode of being, the hermeneutical question: how can language (the being that can be understood) be understood, today? There is no work of digital literary art that expresses this dilemma better 
than Noah Fruin's Screen, ${ }^{3}$ on which I conclude my book and this essay: in this full immersion experience, realized for the Brown virtual reality environment, we are invited to $\mathrm{read} /$ listen to three stories, written in flickering characters on the walls of the Cave, like the pages of a tridimensional book or a virtual version of the origins of Writing, the latest version of the House of language. These stories are memories and as we try to read/evoke them, the characters start to peel off the walls. We can try to salvage them, pushing them back onto the walls by hitting them with a laser pointer, but this playful exercise becomes ever more frantic as the crumbling accelerates. Until we give up and the words start to swirl faster and faster around us until they pile up or better condense together in an undecipherable white cloud in which we are immersed. As the voice speaking to us from the depth of the Cave invites us to start "playing" again, to try and re-compose a meaning from the scattered, fragmentary words, the pieces of stories, of memories, of language slowly resurfacing on the walls, we have time to reflect that perhaps this painstaking task is (still) the paradoxical goal of the literary work in the age of programmable devices.

${ }^{1}$ The definition can be found in a dialogue-interview with Roger Chartier at: http://www.carmencovito.com/archivio/saggi regazzoni.html (Web, August 16, 2012).

${ }^{2}$ I refer to the international festival of digital arts "Interrupt," held at Brown University in 2008. (http://www.brown.edu/Project/Interrupt 2008/) (June 25, 2012): "Why "Interrupt"? In computing, a hardware interrupt request or IRQ is used to prioritize the execution of certain processes over others. It is a command sent to the processor to get its attention, signaling the need to initiate a new operation. In the context of contemporary art, the act of interruption is a performance that redirects threads of process and lines of thought into fields of new expression. Interrupts trigger the moment when a process of creation yields a public manifestation. The cycle of ongoing work is paused by a challenge, calling for the attention of a provisional community: just as we read ICQ as "I seek you," we can read IRQ as "I argue." In this sense, interrupts articulate critical thresholds at which formal expressions are offered up to (or forced into) new circuits of communication, countering that which came before and making a case for new artistic and political futures.

${ }^{3}$ A short video of the installation is available at: http://www.youtube.com/watch?v=WOwF5KD5BV4 (June 28, 2012).

\section{Works Cited}

Aarseth, Erspen J. Cybertext. Perspectives on Ergodic Literature. Baltimore, Md: The Johns Hopkins University Press, 1997. Print.

Çoover, Robert. "Literary Hypertext: The Passing of the Golden Age." Digital Arts and Culture, Atlanta, Georgia, 1999. Keynote Address. Web. 1 September 2012. http://nickm.com/vox/golden_age.html

Dilthey, Wilhelm. Selected Works. Volume I: Introduction to the Human Sciences, Princeton: Princeton, U.P., 1991 Print. 
Fiorentino, Francesco, ed. Al di là del testo. La critica letteraria e lo studio della cultura. Macerata: Quodlibet, 2011. Print.

Fiormonte, Domenico, ed. Canoni liquidi. Variazione culturale e stabilità testuale dalla Bibbia a Internet. Napoli: Scripta Web, 2011. Print.

Grigorenko, Elena L, Elisa Mambrino, and David D. Preiss. Writing: A Mosaic of New Perspectives. Hoboken: Taylor \&amp; Francis, 2012. Internet resource.

Hayles, N. Katherine. "Intermediation: The Pursuit of a Vision." New Literary History, Volume 38, Number 1, Winter 2007: 99-125. Print.

---, Electronic Literature: New Horizons for the Literary, Notre Dame: University of Notre Dame Press, 2008. Print.

Manovich, Lev. "Cultural Software." Lev Manovich new media, digital humanities, cultural analytics, software studies. Web. June 25, 2012. http://manovich.net/2011/07/14/newarticle-cultural-software-lev-manoich-7142011/

Mazzarella, Arturo. La grande rete della scrittura. La letteratura dopo la rivoluzione digitale. Torino: Bollati Boringhieri, 2008. Print.

Nelson, Theodor H. Literary Machines 93.1. Sausalito CA: Mindful Press , 1992. Print.

Ricciardi, Mario, ed. Oltre il testo, gli ipertesti. Torino: Bollati Boringhieri, 1995. Print.

Riva, Massimo. Il futuro della letteratura. L'opera d'arte letteraria nell'epoca della sua (ri)producibilità digitale. Napoli: Scripta Web, 2011. Print.

Wardrip-Fruin, Noah. Expressive Processing. Digital Fictions, Computer Games, and Software Studies. Cambridge, Mass.: MIT Press, 2011. Print.

---, Screen (2002-05) with Sascha Becker, Josh Carroll, Robert Coover, Shawn Greenlee, and Andrew McClain, http://www.hyperfiction.org/screen/. Web. September 10, 2012. 